\title{
TEORIA DOS DIREITOS FUNDAMENTAIS: EVOLUÇÃO HISTÓRICO- POSITIVA, REGRAS E PRINCÍPIOS
}

\section{THEORY OF ESSENTIAL RIGHTS: HISTORICAL-POSITIVE EVOLUTION, RULES AND PRINCIPLES}

Dicesar Beches Vieira Junior ${ }^{1}$

\begin{abstract}
RESUMO: O presente artigo versa sobre a Teoria dos Direitos Fundamentais em seu aspecto evolutivo histórico-positivo e conceitual. Em segundo momento faz-se discussão sobre a demarcação das normas de direitos fundamentais como regras e como princípios. Não obstante existirem normas de direitos fundamentais em sentido formal e em sentido material vê-se em Alexy a importância da Teoria dos Direitos Fundamentais Atribuídos para a construção de um sistema de direitos fundamentais, aberto e receptivo a novos direitos fundamentais, desde que referidos a direito fundamental formalmente expresso na Constituição. Mormente os direitos fundamentais encerrarem forte conteúdo axiológico, na nova hermenêutica jurídica, lê-se pós-positivismo, as normas de direitos fundamentais são de suma importância como elementos de interpretação e integração do ordenamento jurídico.
\end{abstract}

Palavras-chaves: Robert Alexy; Normas de Direitos Fundamentais; Evolução Histórico-positiva; Regras; Princípios.

ABSTRACT: The present article discourses over the theory of the essential rights in its historical-political evolving and conceptive aspect. Secondly a discussion about the stablishment of the essential rights as rules and principles is made up. However there are rules of essential rights in formal and material sense. One sees in Alexy the importance if the theory of the essential rights meant to the construction of a system of essential rights, open and receptive to new essential rights, provided that they're reffered to essential right formally expressed on the constitution, mainly the essential rights show strong axiological contents in the legal hermeneutics, it's read postpositivism, the rules of essential rights are extremely important as elements of interpretation and integration of the legal system.

KEYWORDS: Robert Alexy; Rules of Essential Rights; Evolution Historical Positive; Rules; Principles.

\footnotetext{
${ }^{1}$ Mestrando pelas Faculdades Integradas do Brasil - UniBrasil, em Direitos Fundamentais e Democracia. Professor de Direito do Trabalho pela Faculdade Educacional Araucária - Facear.. E-mail: dicesarjr@ hotmail.com
} 
Revista da Faculdade de Direito-RFD-UERJ- Rio de Janeiro, n. 28, dez. 2015

P á g i n a | 74

\section{INTRODUÇÃOO}

Mais do que uma simples teoria interpretativa do ordenamento jurídico, a Teoria dos Direitos Fundamentais, quando analisada em sua evolução histórico-positiva, fundamenta o conceito de normas de direitos fundamentais, imprescindível para a compreensão do ordenamento jurídico moderno, bem como o importante caráter duplo dos direitos fundamentais como regras e como princípios.

O presente artigo inicia-se com um intercurso histórico pelo processo evolutivo dos direitos fundamentais como meras declarações com vistas a conter o poder político dos Estados Absolutistas até sua efetivação enquanto normas de direito positivo e, portanto, eficazes.

Ocorre que nessa evolução histórico-positiva ver-se-á que as normas de direitos fundamentais podem ser englobadas em gerações ou dimensões, como preferem alguns festejados autores do direito constitucional moderno, não obstante ressalta-se que embora a evolução histórica desses direitos dividida didaticamente em gerações não impõe a ideia de exclusão e/ou superação de uma geração pela outra.

Posteriormente analisam-se os direitos fundamentais enquanto norma, tanto em sentido material quanto em sentido formal. Nesse momento faz-se importante discussão entre direitos fundamentais formalmente positivados, ou seja, aqueles que se encontram expressamente e formalmente positivados no texto constitucional e aqueles direitos fundamentais em sentido material, não positivado no texto constitucional, mas, como leciona Robert ALEXY, são direitos fundamentais atribuídos² .

Por fim, sublinha-se que, como se verá, na sua própria evolução históricopositiva, os direitos fundamentais possuem forte carga axiológica. Não por acaso entende MARMELSTEIN que as normas de direitos fundamentais possuem conteúdo ético-normativo lastreado principalmente no princípio da dignidade da pessoa humana ${ }^{3}$.

\footnotetext{
2 ALEXY, Robert. Teoria dos Direitos Fundamentais. Trad. Virgílio Afonso da Silva. São Paulo: Malheiros, 2008, p. 69-76.

${ }^{3}$ No mesmo sentido leciona o processualista Fredie Didier JR que a "expansão e consagração dos direitos fundamentais, que impõem ao Direito positivo um conteúdo ético mínimo que respeite a dignidade da pessoa humana e cuja teoria jurídica se vem desenvolvendo a passos largos". Curso de Direito Processual Civil: v. 1. Salvador: Juspodivm, 2012, p. 29.
} 
Revista da Faculdade de Direito-RFD-UERJ- Rio de Janeiro, n. 28, dez. 2015

P á g i n a | 75

Nesse sentido as normas de direitos fundamentais são comumente confundidas com princípios. Muitas vezes entendem-se as normas de direitos fundamentais como tão somente princípios, negando-se seu nível de regra, como pondera ALEXY, que entende as normas de direitos fundamentais possuírem duplo caráter normativo.

Desta forma, como última discussão do presente artigo, aborda-se a importante diferenciação entre regras e princípios para se pontuar claramente o fato das normas de direitos fundamentais conterem conteúdo normativo duplo, ou seja, integram em seu conteúdo os níveis dos princípios e das regras.

Mormente a importância de se ressaltar os mais diversos entendimentos sobre o assunto, frisa-se que o presente artigo tem por eixo central a Teoria dos Direitos Fundamentais desenvolvida por Robert ALEXY.

\section{DIREITOS FUNDAMENTAIS: EVOLUÇÃO HISTÓRICA E CONCEITUAL.}

Os direitos fundamentais ${ }^{4}$ são um conceito recente na história, pois suas primeiras manifestações relevantes foram com os documentos de cunho declaratório redigidos no bojo das revoluções políticas de fins do século XVIII, precisamente a Revolução Americana de 1776 e a Revolução Francesa de 1789.

Tais declarações trouxeram em seus textos os ideais da Ilustração ${ }^{5}$, incorporando as ideias políticas dos filósofos iluministas precedentes, como John Locke, e contemporâneos, como Voltaire, Diderot, Montesquieu, Rousseau e Benjamim Franklin, por exemplo.

\footnotetext{
${ }^{4}$ Os direitos fundamentais possuem duas dimensões, uma formal e outra material, de forma que Jorge Miranda conceitua os direitos fundamentais como "os direitos ou as posições jurídicas subjetivas das pessoas enquanto tais, individual ou institucionalmente consideradas, assentes na Constituição, seja na Constituição formal, seja na Constituição material - donde direitos fundamentais em sentido formal e direitos fundamentais em sentido material". MIRANDA, Jorge. Manual de Direito Constitucional. Coimbra: Coimbra, 1998, p. 07.

5 "llustração é a saída do homem da sua menoridade de que ele próprio é culpado. A menoridade é a incapacidade de se servir do entendimento sem a orientação de outrem. Tal menoridade é por culpa própria, se a sua causa não residir na carência de entendimento, mas na falta de decisão e de coragem em se servir de si mesmo, sem a guia de outrem. Sapere aude! Tem a coragem de te servires do teu próprio entendimento! Eis a palavra de ordem do lluminismo. (...) Mas, para esta ilustração, nada mais se exige do que a liberdade; e, claro está, a mais inofensiva entre tudo o que se pode chamar liberdade, a saber, a de fazer um uso público da sua razão em todos os elementos." KANT, Immanuel. Resposta a pergunta: que é llustração? (1784). Trad. Artur Morão. http://www.lusosofia.net/textos/kant_o_iluminismo_1784.pdf. Acesso em 10/08/13.
} 
As declarações de direitos assumiram, inicialmente, a forma de proclamações solenes em que, em articulado orgânico especial, se enunciam os direitos. Depois passaram a constituir o preâmbulo das constituições, na França especialmente. Atualmente, ainda que nos documentos internacionais assumam a forma das primeiras declarações, nos ordenamentos nacionais integram as constituições, adquirindo o caráter concreto de normas jurídicas positivas constitucionais, por isso, subjetivando-se em direito particular de cada povo, como já vimos, configuram declarações constitucionais de direito, o que tem consequência jurídica prática relevante (...). ${ }^{6}$

O início do que posteriormente seria chamado de direitos fundamentais, era, entretanto, a continuidade de longa tradição anglo-saxônica de restrição política e institucional dos poderes do monarca.

Em outras palavras, essas declarações buscaram efetivar liberdades essencialmente individuais, como de manifestação, livre pensamento, reunião, locomoção, livre exercício de atividade profissional, ao lado de liberdades políticas e civis.

Desse modo, o conceito de direitos fundamentais somente adquiriu relevância e consistência - e seu prestigio cultural recente - com o advento da inovadora incorporação, em sua matriz, dos vastos seguimentos socioeconômicos destituídos de riqueza que, pela primeira vez na História, passaram a ser sujeitos de importantes prerrogativas e vantagens jurídicas no plano da vida em sociedade. Esse fato decisivo e inédito somente iria ocorrer a partir da segunda metade do século XIX, na experiência principalmente européia. Não por coincidência, ele se confunde com o advento do Direito do Trabalho. ${ }^{7}$

A passagem dos direitos fundamentais voltados para as liberdades civis e políticas do homem proprietário, conquistada a duras penas pela burguesia européia do século XVIII, para as garantias sociais do homem operário do século XIX, marcou essa reviravolta que segundo GODINHO, garantiu aos direitos fundamentais seu prestigio cultural e jurídico moderno.

Nesse aspecto, a história dos direitos fundamentais perpassa pela evolução no plano filosófico dos chamados direitos humanos como direitos de liberdade.

\footnotetext{
${ }^{6}$ SILVA, José Afonso. Curso de Direito Constitucional Positivo. São Paulo: Malheiros, 2012, p. 175.

7 DELGADO, Mauricio Godinho. Direitos Fundamentais na Relação de Trabalho. Revista de Direitos e Garantias Fundamentais, n. 2, 2007, p. 12.
} 
Revista da Faculdade de Direito-RFD-UERJ- Rio de Janeiro, n. 28, dez. 2015

P á g i n a | 77

Tem-se uma verdadeira evolução das concepções jusnaturalistas para a concepção positivista até o surgimento do chamado neoconstitucionalismo ou póspositivismo $^{8}$.

Nesse diapasão, modificações na sociedade abriram espaço para o surgimento de novos direitos no plano jurídico. Dos direitos fundamentais clássicos de liberdade e poder que exigiam uma atuação negativa do Estado frente ao cidadão, para os direitos sociais, também fundamentais, que exigem uma atuação positiva do Estado.

Para George MARMELSTEIN, o surgimento da Teoria dos Direitos Fundamentais está intrinsecamente ligado ao fim da Segunda Guerra Mundial (1945) e a queda do regime nazista. Leciona MARMELSTEIN que,

\begin{abstract}
O nazismo foi como um banho de água fria para o positivismo kelseniano, que até então era aceito pelos juristas de maior prestígio. (...) Foi diante desse "desencantamento" em torno da teoria pura que os juristas desenvolveram uma nova corrente jusfilosófica que está sendo chamada de pós-positivismo, que poderia muito bem ser chamada de positivismo ético, já que seu propósito principal é inserir na ciência jurídica os valores éticos indispensáveis para a proteção da dignidade humana ${ }^{9}$.
\end{abstract}

Nesses termos, MARMELSTEIN sublinha serem os direitos fundamentais normas jurídicas de forte conteúdo ético. Não apenas ético, mas também voltados para a proteção da dignidade humana ${ }^{10}$.

Não obstante, em razão do caráter eminentemente histórico dos direitos fundamentais, estes não permitem sua definição em termos absolutos.

Segundo Robert ALEXY, os direitos fundamentais possibilitam a formação das mais variadas teorias, assim,

Teorias históricas, que explicam o desenvolvimento dos direitos fundamentais, teorias filosóficas, que se empenham em esclarecer seus fundamentos, e teorias sociológicas, sobre a função dos direitos fundamentais no sistema social, são apenas três exemplos ${ }^{11}$.

8 Sobre o Neoconstitucionalismo conferir obra: CARBONELL, Miguel. et al. Neoconstitucionalismo (s). Madrid: Trotta, 2003.

${ }_{9}$ MARMELSTEIN, George. Curso de Direitos Fundamentais. São Paulo: Atlas, 2008, p. 1011.

10 "A dignidade humana é, portanto, a base axiológica desses direitos". Ibidem; p. 18.

11 ALEXY, Robert. Teoria dos Direitos Fundamentais. Trad. Virgílio Afonso da Silva. São Paulo: Malheiros, 2008, p. 31. 
Revista da Faculdade de Direito-RFD-UERJ- Rio de Janeiro, n. 28, dez. 2015

Nesse sentido, ALEXY se propõe a formular uma Teoria Geral dos Direitos Fundamentais da Constituição Alemã. Sublinha ainda o autor que sua teoria visa três aspectos: ela é uma teoria dos direitos fundamentais da Constituição Alemã, é uma teoria jurídica e por fim, uma teoria geral.

Segundo Norberto BOBBIO, “(...) os direitos não nascem todos de uma vez. Nascem quando devem ou podem nascer. Nascem quando há o aumento do poder do homem sobre o homem (...) ou cria novas ameaças à liberdade do indivíduo, ou permite novos remédios para as suas indigências" $" 12$.

Em sua evolução histórica a vinculação essencial dos direitos fundamentais à liberdade e à dignidade da pessoa humana, como valores históricos, culturais e filosóficos, conduz sem óbices, segundo BONAVIDES, ao significado universal inerentes a esses direitos ${ }^{13}$.

Por sua vez, a doutrina classifica os direitos fundamentais, em sua evolução histórica, como direitos de primeira, segunda e terceira gerações, a depender do momento histórico em que foram reconhecidos e positivados ${ }^{14}$.

Nessa testilha, a primeira geração dos direitos fundamentais deita raízes nas Declarações do século XVIII, sendo a primeira a do Estado da Virgínia de 1776. Todavia, a que realmente marcaria os direitos fundamentais de primeira geração foi a Declaração dos Direitos do Homem e do Cidadão que sintetizou as aspirações políticofilosóficas da Revolução Francesa de 1789.

Consubstanciam-se a primeira geração de direitos fundamentais os direitos de liberdade, notadamente os direitos civis e políticos. Segundo BONAVIDES,

(...) esses direitos têm por titular o indivíduo, são oponíveis ao Estado, traduzem-se como faculdades ou atributos da pessoa e ostentam uma

\footnotetext{
12 BOBBIO, Norberto. A Era dos Direitos. Rio de Janeiro: Campos, 1992, p. 06.

${ }^{13}$ BONAVIDES, Paulo. Curso de Direito Constitucional. São Paulo: Malheiros, 2009, p. 562.

${ }^{14}$ No presente artigo adota-se a terminologia "gerações", não obstante se faz presente a crítica de Ingo W. SARLET a essa terminologia e sua preferência pela terminologia "dimensões". Segundo o autor, "Com efeito, não há como negar que reconhecimento progressivo de novos direitos fundamentais tem o caráter de um processo cumulativo, de complementaridade, e não de alternância, de tal sorte que o uso da expressão "gerações" pode ensejar a falsa impressão da substituição gradativa de uma geração por outra, razão pela qual há quem prefira o termo 'dimensões' dos direitos fundamentais, posição esta que aqui optamos por perfilhar, na esteira da mais moderna doutrina". A Eficácia dos Direitos Fundamentais. Porto Alegre: Livraria do Advogado, 2009, p. 45.
} 
subjetividade que é seu traço mais característico; enfim, são direitos de resistência ou de oposição perante o Estado ${ }^{15}$.

Em outras palavras, os direitos fundamentais de primeira geração guardam uma exigência de prestação negativa por parte do Estado o que enseja em uma valorização da liberdade individual.

Não por acaso a liberdade de consciência, de culto, de reunião e a inviolabilidade do domicílio são exemplos de direitos de primeira geração que tem como titular o homem considerado individualmente.

O Estado deve abster-se, prestação negativa, de interferir na esfera particular, íntima, individual, do homem, do cidadão.

Ainda no seu aspecto histórico, a consagração dos direitos fundamentais de primeira geração dá-se pelo movimento impetrado pela burguesia ascendente dos séculos XVIII e XIX com vistas à limitação do poder absoluto concentrado nas mãos do monarca $^{16}$.

A burguesia ao reclamar direitos de influenciar a política, tendo em vista o crescimento de seu poder econômico, buscou que se assegurasse a separação dos poderes e que reclamasse direitos individuais num documento constitucional como garantias de liberdade.

Nesse quadro político-social é compreensível que os direitos fundamentais de primeira geração sejam direitos de liberdade que impõe ao Estado uma prestação negativa de não intervenção, precipuamente, na propriedade privada, nas relações mercantis, ou seja, no campo econômico já sob domínio da burguesia ascendente.

Sob outro aspecto, os direitos fundamentais de segunda geração buscam assegurar os direitos sociais, econômicos e culturais. Seu fundamento pode ser encontrado no principio da igualdade e diferentemente dos de primeira geração os de segunda obrigam o Estado a prestações positivas com o fim de realização da justiça social.

O impacto da industrialização e os graves problemas sociais e econômicos que a acompanharam, as doutrinas socialistas e a constatação de que a

\footnotetext{
15 Ibidem; p. 563-564.

16 Para mais ver: FACHIN, Zulmar. Curso de Direito Constitucional. Rio de Janeiro: Editora Forense, 2012, p. 211-213.
} 
consagração formal de liberdade e igualdade não gerava a garantia do seu efetivo gozo acabaram, já no decorrer do século XIX, gerando amplos movimentos reivindicatórios e o reconhecimento progressivo de direitos, atribuindo ao Estado comportamento ativo na realização de justiça social. A nota distintiva destes direitos é a sua dimensão positiva, uma vez que cuida não mais de evitar a intervenção do Estado na esfera da liberdade individual, mas, sim, na lapidar formulação de C. Lafer, de propiciar um "direito de participar do bem-estar social"17.

Faz-se importante observar que os direitos fundamentais de segunda geração não englobam apenas prestações positivas por parte do Estado, mas também as assim denominadas "liberdades sociais", como por exemplo, as liberdades de sindicalização e o direito de greve, bem como a positivação constitucional de direitos fundamentais do trabalhador, como o direito as férias, o repouso semanal remunerado, a limitação da jornada de trabalho, a garantia de uma remuneração mínima, para citar alguns dos mais representativos ${ }^{18}$.

Notadamente apesar de muitos dos direitos de segunda geração tenham por titulares indivíduos, como o trabalhador, diz-se que são sociais por estarem intrinsecamente ligados as reivindicações sociais que marcaram o século XIX e primeira metade do século XX.

Nesse sentido, BONAVIDES pontua que os direitos fundamentais de segunda geração,

São os direitos sociais, culturais e econômicos bem como os direitos coletivos ou de coletividades, introduzidos no constitucionalismo das distintas formas de Estado Social, depois que germinaram por obra da ideologia e da reflexão antiliberal do século XX.

Tais direitos enfrentaram forte questionamento de sua juridicidade, de tal forma que foram relegados a normas programáticas, meros conselhos, enfrentando assim uma crise de observância e execução, cujo fim foi marcado pelo fato das recentes Constituições, como a brasileira, que adotaram o princípio da aplicabilidade imediata dos direitos fundamentais ${ }^{19}$.

17 SARLET, Ingo W. A Eficácia dos Direitos Fundamentais. Porto Alegre: Livraria do Advogado, 2009, p. 47.

18 Ibidem; p. 48.

19 "Somente em hipóteses excepcionais, previstas na Constituição, um direito fundamental exige intermediação normativa de órgão estatal para ser aplicado ao caso concreto. Pode-se 
Revista da Faculdade de Direito-RFD-UERJ- Rio de Janeiro, n. 28, dez. 2015

Em nossa Constituição o princípio da aplicabilidade imediata encontra-se positivado no art. $5^{\circ}, \S 1^{\circ}$, segundo o qual as normas de direitos fundamentais têm aplicação imediata.

Ainda no que tange ao intercurso histórico dos direitos fundamentais, no ultimo quartel do século $\mathrm{XX}$ surgiram os direitos fundamentais de terceira geração fundamentados no princípio da solidariedade ou da fraternidade.

Os direitos de terceira geração são notadamente marcados pela titularidade difusa ou coletiva, em outras palavras, a titularidade desses direitos não repousa sobre o homem isoladamente considerado, mas sob a coletividade, os grupos sociais.

São exemplos de direitos fundamentais de terceira geração: o direito ao meio ambiente, o direito a proteção ao patrimônio histórico e cultural da humanidade, o direito a paz, entre outros igualmente difusos.

Segundo BOBBIO, é a Declaração Universal dos Direitos do Homem de 1948 que deu início à terceira geração dos direitos fundamentais, pois essa Declaração,

Põe em movimento um processo em cujo final os direitos do homem deverão ser não mais apenas proclamados ou apenas idealmente reconhecidos, porém efetivamente protegidos até mesmo contra o próprio Estado que os tenha violado $^{20}$.

Igualmente leciona SARLET que a nota distintiva dos direitos fundamentais de terceira dimensão, como prefere o autor, reside basicamente em sua titularidade coletiva, muitas vezes indefinida e indeterminável ${ }^{21}$.

\footnotetext{
Com efeito, um novo pólo jurídico de alforria do homem se acrescenta historicamente aos da liberdade e da igualdade. Dotados de altíssimo teor de humanismo e universalidade, os direitos da terceira geração tendem a cristalizar-se no fim do século XX enquanto direitos que não se destinam especificamente à proteção dos interesses de um indivíduo, de um grupo ou de um determinado Estado. Tem primeiro por destinatário o gênero humano mesmo, num momento expressivo de sua afirmação como valor supremo em termos de existencialidade concreta ${ }^{22}$.
}

mencionar, como exemplo, o direito de o trabalhador participar nos lucros ou resultados da empresa, 'conforme definido em lei' (art. $7^{\circ}$, inciso XI). Nessa hipótese, mesmo se tratando de um direito fundamental, entendeu-se que ele somente poderia ser aplicado ao caso concreto após a edição da lei exigida. A Lei 10.101, de 19 de dezembro de 2000, veio dispor sobre a participação dos trabalhadores nos lucros ou resultados da empresa". FACHIN, Zulmar. Curso de Direito Constitucional. Rio de Janeiro: Forense, 2012, p. 239.

20 BOBBIO, Norberto. Op. cit, p. 30.

${ }^{21}$ SARLET, Ingo W. Op. cit, p. 49.

22 BONAVIDES, Paulo. Op. cit, p. 569. 
Revista da Faculdade de Direito-RFD-UERJ- Rio de Janeiro, n. 28, dez. 2015

Desse modo, com os direitos fundamentais de terceira geração completa-se o lema da Revolução Francesa de 1789: liberdade, igualdade e fraternidade.

Celso LAFER leciona que,

\begin{abstract}
Enquanto dos direitos de primeira geração (direitos civis e políticos) - que compreendem as liberdades clássicas, negativas ou formais - realçam o princípio da liberdade e os direitos de segunda geração (direitos econômicos, sociais e culturais) - que se identificam com as liberdades positivas, reais ou concretas - acentuam o princípio da igualdade, os direitos de terceira geração, que materializam poderes de titularidade coletiva atribuídos genericamente a todas as formações sociais, consagram o principio da solidariedade e constituem um momento importante no processo de desenvolvimento, expansão e reconhecimento dos direitos humanos, caracterizados, enquanto valores fundamentais indisponíveis, pela nota de uma essencial inexauribilidade ${ }^{23}$.
\end{abstract}

Hodiernamente há autores que defendem direitos fundamentais de quarta e até quinta geração ${ }^{24}$. Notadamente, BONAVIDES afirma que a "globalização política na esfera da normatividade jurídica introduz os direitos de quarta geração, que, aliás, corresponde a derradeira fase de institucionalização do Estado social"25.

Segundo ao autor, os direitos de quarta geração consubstanciam-se no direito à democracia, à informação e ao pluralismo. Seguindo em sua classificação, BONAVIDES conceitua o direito à paz como um direito fundamental de quinta geração $^{26}$.

Mormente haver na evolução histórica dos direitos fundamentais diferentes gerações/dimensões, essas diferentes gerações de direitos fundamentais não se excluem, mas se complementam.

\footnotetext{
${ }^{23}$ LAFER, Celso. Desafios: ética e política. São Paulo: Siciliano, 1995, p. 239.

${ }^{24}$ Ressalte-se o posicionamento defendido pelo constitucionalista londrinense Zulmar Fachin, segundo o qual o direito a água é um direito fundamental de sexta dimensão, como prefere o autor. Nesse sentido, "O direito fundamental a água potável, como direito de sexta dimensão, significa um acréscimo ao acervo de direitos fundamentais, nascidos, a cada passo, no longo caminhar da Humanidade. Esse direito fundamental, necessário à existência humana e a outras formas de vida, necessita de tratamento prioritário das instituições sócias e estatais, bem como por parte de cada pessoa humana". FACHIN, Zulmar. Curso de Direito Constitucional. Rio de Janeiro: Forense, 2012, p. 229.

${ }^{25}$ BONAVIDES, Paulo. Op. cit, p. 571.

${ }^{26}$ Ibidem; p. 582-583.
} 
Revista da Faculdade de Direito-RFD-UERJ- Rio de Janeiro, n. 28, dez. 2015

Os direitos de liberdade complementam os direitos econômicos e sociais que, juntos, complementam os direitos de terceira geração, quais sejam, os fundamentados no princípio da fraternidade ou solidariedade.

Nesse aspecto, é necessário observar-se que historicamente os ideais jusnaturalistas foram aprimorados, ao passar das leis naturais para leis positivas, de forma que o jusnaturalismo perdeu espaço para o positivismo no que tange aos direitos fundamentais.

Não obstante, o próprio positivismo vê-se modernamente superado pelo póspositivismo ou neoconstitucionalismo, como se prefere em terrae brasilis ${ }^{27}$, paradigma teórico metodológico para a análise dos direitos fundamentais.

\begin{abstract}
A superação histórica do jusnaturalismo e o fracasso político do positivismo abriram caminho para um conjunto amplo e ainda inacabado de reflexões acerca do Direito, sua função social e sua interpretação. O pós-positivismo é a designação provisória e genérica de um ideário difuso, no qual se incluem a definição das relações entre valores, princípios e regras, aspectos da chamada nova hermenêutica e a teoria dos direitos fundamentais ${ }^{28}$.
\end{abstract}

Em outras palavras, essa nova hermenêutica jurídica possibilitou a interação do Direito com os valores, o que não era possível na lógica puramente positivista que preceituava a separação da ciência jurídica com a axiologia.

Para poderem beneficiar-se do amplo instrumental do Direito, migrando da filosofia para o mundo jurídico, esses valores compartilhados por toda a comunidade, em dado momento e lugar, materializam-se em princípios, que passam a estar abrigados na Constituição, explicita ou implicitamente.

27 Diz-se: neoconstitucionalismo in terra brasilis, por que como sublinhado anteriormente não existe apenas um neoconstitucionalismo, mas vários, com matizes diferentes dependendo do autor e do contexto sócio-histórico, e normativo, em que se analisa o pós-positivismo normativo ou neoconstitucionalismo. Nesse sentido, leciona Virgilio Afonso da Silva, que, "Se é verdade que a interpretação constitucional não é igual à interpretação jurídica geral - e eu estou convencido de que, pelo menos em parte, não é -, então, é tarefa da doutrina constitucional discutir de forma concreta não somente o método ou conjunto de métodos - desde que compatíveis - que ache aplicável à Constituição Brasileira, mas também iniciar uma discussão de base, isto é, uma discussão de conteúdo, que vá além da discussão metodológica. (...) Não se pode querer fazer direito constitucional alemão no Brasil. Com isso fica claro que não se quis fazer, aqui, uma manifestação por uma volta aos métodos clássicos de interpretação jurídica. $O$ que se quis foi mostrar que a ânsia em rejeitá-los mais prejudica do que fomenta a discussão sobre especificidades da interpretação constitucional". SILVA, Virgílio Afonso da. Interpretação Constitucional e Sincretismo Metodológico. p. 115 - 143. In: SILVA, Virgílio Afonso da (Org.). Interpretação Constitucional. São Paulo: Malheiros, 2007, p. 141.

28 BARROSO, Luís Roberto. Fundamentos teóricos e filosóficos do novo Direito Constitucional brasileiro. Jus Navigandi, Teresina, ano 6, n. 59, out. 2002. Disponível em: http://jus2.uol.com.br/doutrina/texto.asp?id=3208. Acesso em 22 de jan. 2014, p. 02. 


\begin{abstract}
Alguns nela já se inscreviam de longa data, como a liberdade e a igualdade, sem embargo da evolução de seus significados. Outros, conquanto clássicos, sofreram releituras e revelaram novas sutilezas, como a separação dos Poderes e o Estado democrático de direito. Houve, ainda, princípios que se incorporaram mais recentemente ou, ao menos, passaram a ter uma nova dimensão, como o da dignidade da pessoa humana, da razoabilidade, da solidariedade e da reserva de justiça ${ }^{29}$.
\end{abstract}

Nesse diapasão, os direitos fundamentais não são conceituados como valores universais a atemporais, originários de uma razão natural e fora da história, mas sim, como uma construção histórico-cultural, com base em axiomas expressos por princípios, esses também expressos ou implícitos na Constituição.

Verifica-se, não obstante, a existência de várias correntes jusfilosóficas que buscam um fundamento para os direitos fundamentais com a finalidade de reforçá-los no plano jurídico positivado e garantir a sua eficácia material.

Novamente leciona BOBBIO que, é ilusório buscar um fundamento absoluto para os direitos fundamentais, até mesmo, em razão da variedade de direitos tidos como fundamentais.

Nesse sentido, a fixação de uma fundamentação absoluta a esses direitos estaria a serviço contra o desenvolvimento desses mesmos direitos. Para BOBBIO, "o fundamento absoluto não é apenas uma ilusão; em alguns casos, é também um pretexto para defender posições conservadoras ${ }^{30}$, , ou seja, o contrário do que se espera da eficácia normativa de um direito fundamental.

Notadamente, a dificuldade em se harmonizar as inúmeras concepções sobre os fundamentos dos direitos fundamentais levou ao questionamento da utilidade prática do estudo desses fundamentos. De forma que, mais importante que encontrar fundamentos absolutos para os direitos fundamentais é estabelecer fórmulas para protegê-los e tornálos eficazes ${ }^{31}$.

\footnotetext{
29 Ibidem; p. 02.

30 BOBBIO, Norberto. A Era dos Direitos. Rio de Janeiro: Campos, 1992, p. 22.

31 Sublinha-se interessante discussão sobre a dimensão objetiva dos direitos fundamentais. Tendo os direitos fundamentais surgido com o objetivo de assegurar as liberdades civis, individuais das pessoas, configurando uma prestação negativa do Estado, eles surgiram, portanto, como direitos subjetivos. Em segundo momento se questionou se esses direitos teriam também uma dimensão objetiva. Sobre as dimensões dos direitos fundamentais leciona Steinmetz: "A vinculação aos direitos fundamentais tem dupla dimensão: primeiramente, é uma vinculação negativa, porque o legislador não poderá intervir nos direitos fundamentais,
} 


\section{DIREITOS FUNDAMENTAIS COMO NORMA: CONTEÚDO MATERIAL E FORMAL.}

Majoritariamente, a doutrina tem defendido o ponto segundo o qual os direitos fundamentais possuem como característica marcante o seu conteúdo ético-normativo consubstanciado no princípio da dignidade da pessoa humana, principalmente ${ }^{32}$.

Segundo esse pensamento, o princípio da dignidade da pessoa humana, positivado em nossa Constituição em seu art. $1^{\circ}$, III, dá lastro aos direitos fundamentais.

Mormente esse entrelaçamento dos direitos fundamentais com o princípio da dignidade da pessoa humana, esse posicionamento, embora majoritário, não é uniforme.

Dentre seus críticos se sita o constitucionalista português J. J. Gomes CANOTILHO, segundo o qual essa concepção "expulsa do catálogo material dos direitos todos aqueles que não tenham um radical subjetivo, isto é, não pressuponham a idéia-princípio da dignidade da pessoa humana” ${ }^{\circledR 3}$.

Nesse sentido resultar-se-ia em uma teoria dos direitos fundamentais constitucionalmente, inadequada.

Nessa perspectiva os direitos fundamentais ditos "formalmente constitucionais" são os enunciados por normas com valor constitucional formal,

restringindo-os, ou autorizar que um outro poder público intervenha (Executivo e Judiciário), sem fundamento constitucional; e depois, é uma vinculação positiva, porque cabe ao legislador criar as estruturas normativas configuradoras, reguladoras, procedimentais, organizatórias para a plena eficácia dos direitos fundamentais. A vinculação negativa fundamenta-se na dimensão subjetiva dos direitos fundamentais, enquanto uma esfera individual livre de ingerência estatal, exceto em hipótese justificada constitucionalmente. A vinculação positiva funda-se na dimensão objetiva dos direitos fundamentais, obrigando o legislador a tomar providências que garantam a vigência e a eficácia desses direitos". STEINMETZ, Wilson Antonio. Colisão de Direitos Fundamentais e Princípio da Proporcionalidade. Porto Alegre: Livraria do Advogado, 2001, p. 31. Portanto, a dimensão objetiva dos direitos fundamentais impõe ao Estado uma prestação positiva no sentido de um poder/dever de criação de mecanismos de proteção dos direitos fundamentais.

32 "Normas de direitos fundamentais são normas. Por isso, o conceito de norma de direito fundamental compartilha de todos os problemas que dizem respeito ao conceito de norma". ALEXY, Robert. Op. cit, p. 51. Em outras palavras ALEXY ressalta a dificuldade de se conceituar normas de direito fundamental devido o sentido polissêmico da própria palavra "norma".

${ }^{33}$ GOMES CANOTILHO, José Joaquim. Direito Constitucional e Teoria da Constituição. Coimbra: Almedina, 1998, p. 373. 
Revista da Faculdade de Direito-RFD-UERJ- Rio de Janeiro, n. 28, dez. 2015

P á g i n a | 86

enquanto os direitos fundamentais em sentido material seriam os constantes nos tratados e convenções de direito internacional, não-positivados constitucionalmente.

Em busca de encontrar uma compatibilidade entre as normas de direito fundamental e as regras constitucionais, mantendo-se a coerência interna da Constituição, no caso a Constituição Alemã, Robert ALEXY encontra no positivismo o conceito do que sejam normas de direitos fundamentais.

Segundo ALEXY, "Mais conveniente que basear o conceito de norma de direito fundamental em critérios substanciais e/ou estruturais é vinculá-lo a um critério formal, relativo a forma de sua positivação" ${ }^{34}$.

$\mathrm{O}$ referido autor sublinha ser normas de direitos fundamentais aquelas contidas nas disposições dos arts. $1^{\circ}$ a 19 , da Constituição Alemã, bem como as disposições garantidoras de direitos individuais. Conclui ALEXY, que "normas de direitos fundamentais são as normas diretamente expressas por essas disposições" ${ }^{35}$.

Nesse diapasão, a definição das normas de direitos fundamentais perpassam por um entendimento que são fruto mais de uma ação política, de positivação, do que a atuação interpretativa de um conteúdo de uma determinada norma.

Ressalte-se que apesar de ALEXY conceituar as normas de direitos fundamentais como aquelas positivadas pela Constituição Alemã como normas de direito fundamental, o autor não defende um sistema fechado de direitos fundamentais.

Em sentido oposto, defende ALEXY a existência de normas de direitos fundamentais não expressamente enunciadas pela Constituição. Essas normas de conteúdo fundamental são denominadas de "normas de direitos fundamentais atribuídas".

As normas de direito fundamental, podem, portanto, ser divididas em dois grupos: as normas de direito fundamental estabelecidas diretamente pelo texto constitucional e as normas de direito fundamental atribuídas ${ }^{36}$.

${ }^{34}$ ALEXY, Robert. Teoria dos Direitos Fundamentais. Trad: Virgílio Afonso da Silva. São Paulo: Malheiros, 2008, p. 68.

35 Ibidem; p. 68-69.

${ }^{36}$ ALEXY, Robert. Ibidem; p. 73. 
Pontua-se que a divisão realizada por CANOTILHO, segundo o qual os direitos fundamentais se dividem em dois grandes grupos de direitos identificados segundo os meios pelos quais essas normas surgem ou se afirmam.

De forma que, para CANOTILHO, como já visto, as normas de direitos fundamentais são "formalmente fundamentais" estabelecidas a partir da positivação pelo Legislativo no ordenamento jurídico- constitucional, e há aquelas normas "materialmente fundamentais", não positivadas, mas possuidoras de um valor fundamental.

Para ALEXY, a norma de direito fundamental atribuída surge da evolução interpretativa de uma norma fundamental expressa, ou seja, positivada no texto constitucional. De forma que a validade das normas atribuídas se assenta no referencial adequado de um direito fundamental positivado.

(...) uma norma atribuída é valida, e é uma norma de direito fundamental, se, para tal atribuição a uma norma diretamente estabelecida pelo texto constitucional, for possível uma correta fundamentação referida a direitos fundamentais ${ }^{37}$.

Não obstante, a teoria dos direitos fundamentais atribuídos possua um efeito positivo no sentido de se constituir um meio de criação de novos direitos fundamentais, ou seja, de manter o sistema aberto, ela também enseja relativa insegurança.

Primeiramente, por não definir com exatidão quais são os direitos fundamentais, e em seguida, dificulta a tarefa de interpretar e legislar, tendo em vista que se impõe uma obrigação de não contrariar uma norma de conteúdo fundamental não exato.

Assim como ALEXY, Ingo W. SARLET também defende a existência de direitos fundamentais fora do catálogo constitucional, mas pontua que:

(...) direitos fundamentais fora do catálogo somente poderão ser os que constem, ou não, do texto constitucional - por seu conteúdo e importância possam a ser equiparados aos integrantes do rol elencado no Titulo II de nossa Lei Fundamental. Ambos os critérios (substância e relevância) se encontram agregados entre si e são imprescindíveis para o conceito materialmente aberto de direitos fundamentais ${ }^{38}$.

${ }^{37}$ ALEXY, Robert. Ibidem; p. 74.

38 SARLET, Ingo W. A Eficácia dos Direitos Fundamentais. Porto Alegre: Livraria do Advogado, 2009, p. 92. 
José Afonso da SILVA, igualmente, identifica nos direitos fundamentais um conteúdo de essencialidade. Segundo este autor, que entende melhor terminologia a de direitos fundamentais do homem:

(...) no qualificativo fundamentais acha-se a indicação de que se trata de situações jurídicas sem as quais a pessoa humana não se realiza, não convive e, às vezes, nem mesmo sobrevive; fundamentais do homem no sentido de que a todos, por igual, devem ser, não apenas formalmente reconhecidos, mas concreta e materialmente efetivados ${ }^{39}$.

Assim, os direitos fundamentais, em sentido material, são pretensões que surgem no decorrer da história e se revelam a partir do valor da dignidade da pessoa humana.

\section{DIREITOS FUNDAMENTAIS COMO REGRAS E COMO PRINCÍPIOS}

Ainda no tocante a uma construção de uma Teoria dos Direitos Fundamentais enquanto paradigma interpretativo do próprio ordenamento jurídico, que como sublinhado anteriormente perpassa pela conceituação histórico-positiva dos direitos fundamentais bem como a definição de seu conteúdo formal e material.

Fazem-se necessário a diferenciação entre normas de direitos fundamentais como regras e como princípios. De forma que as normas de direitos fundamentais costumam serem qualificadas como princípios.

\section{Pontifica BARROSO que,}

Princípios constitucionais incidem sobre o mundo jurídico e sobre a realidade fática de diferentes maneiras. Por vezes, o princípio será fundamentado direto de uma decisão. De outras vezes, sua incidência será indireta, condicionando a interpretação de determinada regra ou paralisando sua eficácia. Relembrese que entre regras e princípios constitucionais não há hierarquia jurídica, como decorrência do princípio instrumental da unidade da Constituição, embora alguns autores se refiram a uma hierarquia axiológica, devido ao fato de os princípios condicionarem a compreensão das regras e até mesmo, em certas hipóteses, poderem afastar sua incidência ${ }^{40}$.

Ocorre que, como sublinhado anteriormente, existe uma diferença entre normas de direitos fundamentais e princípios puros, não obstante a confusão ocorra devido a

39 SILVA, José Afonso. Curso de Direito Constitucional Positivo. São Paulo: Malheiros, 2012 , p. 178.

40 BARROSO, Luis Roberto. Curso de Direito Constitucional Contemporâneo: os conceitos fundamentais e a construção do novo modelo. São Paulo: Saraiva, 2009, p. 318. 
Revista da Faculdade de Direito-RFD-UERJ- Rio de Janeiro, n. 28, dez. 2015

forte carga axiológica presente nos direitos fundamentais, bem como sua posição hierárquica superior no ordenamento jurídico.

Mormente o fato de que existem normas de direitos fundamentais que são princípios, é necessário realizar uma diferenciação entre normas como regras e normas como princípios.

Segundo ALEXY,

A distinção entre regras e princípios constitui, além disso, a estrutura de uma teoria normativo-material dos direitos fundamentais e, com isso, um ponto de partida para a resposta a pergunta acerca da possibilidade e dos limites da racionalidade no âmbito dos direitos fundamentais. Nesse sentido a distinção entre regras e princípios é uma das colunas-mestras do edifício da teoria dos direitos fundamentais ${ }^{41}$.

O Direito atual encontra-se composto por regras e princípios e observa-se que as normas legislativas são em sua maioria regras enquanto que as normas constitucionais, no que tange aos direitos fundamentais e a justiça social, são em sua maioria princípios.

Si el derecho sólo estuviese compuesto de reglas no sería insensato pensar en la "maquinización" de su aplicación por medio de autómatas pensantes, a los que se les porporcionaría el hecho y nos darían la respuesta. Estos autómatas tal vez podrían hacer uso de los principales esquemas lógicos para la aplicación de reglas normativas: el silogismo judicial y la subsunción del supuesto de hecho concreto en el supuesto abstracto de la norma. Ahora bien, tal idea, típicamente positivista, carece totalmente de sentido en la medida en que el derecho contenga princípios ${ }^{42}$.

Ressalta-se, como será visto adiante, que o ponto nodal dessa questão encontrase no conceito e aplicação concreta dos direitos fundamentais.

Em primeiro lugar, as regras são normas que se orientam pela técnica do tudo ou nada, ou seja, não há como ponderar regras aparentemente conflitantes.

A diferença entre princípios jurídicos e regras jurídicas é de natureza lógica. Os dois conjuntos de padrões apontam para decisões particulares acerca da obrigação jurídica em circunstancias específicas, mas distinguem-se quanto a natureza da orientação que oferecem. As regras são aplicáveis a maneira do tudo ou nada. Dados os fatos que uma regra estipula, então ou a regra é válida, e neste caso a resposta que ela fornece deve ser aceita, ou não é válida, e neste caso em nada contribui para a decisão ${ }^{43}$.

41 ALEXY, Robert. Teoria dos Direitos Fundamentais. Trad: Virgílio Afonso da Silva. São Paulo: Malheiros, 2008, p. 85.

42 ZAGREBELSKY, Gustavo. El derecho dúctil. Trotta: Madrid, 2007, p. 111.

43 DWORKIN, Ronald. Levando os direitos a sério. São Paulo: Martins Fontes, 2002, p. 39. 
Revista da Faculdade de Direito-RFD-UERJ- Rio de Janeiro, n. 28, dez. 2015

Pelo método da subsunção o fato se submete ao suporte fático abstrato da regra e esta é aplicada ao caso concreto em tela. Os princípios, por outro lado, são normas semanticamente abertas, ponderáveis e quando colidentes não necessariamente eliminam a incidência da outra ${ }^{44}$.

Enquanto as regras podem ser interpretadas tendo por objeto a vontade objetiva do legislador expressa na construção gramatical da própria regra, os princípios mais do que analisados em sua linguagem precisam ser entendidos em seu ethos ${ }^{45}$.

En pocas palabras, a las reglas "se obedece" y, por ello, es importante determinar con precisión los preceptos que el legislador establece por medio de las formulaciones que contienen las reglas; a los princípios, en cambio, "se presta adhesión" y, por ello, és importante comprender el mundo de valores, las grandes opciones de cultura jurídica de las que forman parte y a las que las palabras no hacen sino una simple alusión ${ }^{46}$.

As regras proporcionam ao jurisdicionado, que somos todos nós, um critério objetivo para pautar suas ações, elas dizem de forma clara o que se deve e o que não se deve fazer o que se é permitido e o que não é permitido. Enquanto os princípios não dizem nada objetivamente, todavia, são critérios para se tomar posição diante de casos concretos que parecem indeterminados ${ }^{47}$.

Nesse imbricado meio se insere a temática dos Direitos Fundamentais. Nesse contexto, faz-se necessário analisar a questão do suporte fático das regras e dos princípios constitucionais, principalmente dos direitos fundamentais ${ }^{48}$.

As regras possuem suporte fático abstrato, ou seja, toda regra por possuir um suporte fático abstrato antevê de forma objetiva e geral um acontecimento fático que se dá no mundo real.

44 "Os princípios possuem uma dimensão que as regras não tem - a dimensão do peso ou importância. Quando os princípios se intercruzam (...), aquele que vai resolver o conflito tem levar em conta a força relativa de cada um. Esta não pode ser, por certo, uma mensuração exata e o julgamento que determina que um princípio ou uma política particular é mais importante que a outra freqüentemente será objeto de controvérsia". Ibidem; p. 42.

45 ZAGREBELSKY, Gustavo. Op. cit, 2007, p. 110.

46 Ibidem; p. 110.

47 Ibidem; p. 111.

48 Para Zagrebelsky os princípios carecem de suporte fático. Nesse sentido. Cf. ZAGREBELSKY, Gustavo. Op. cit, 2007, p. 110. 
Revista da Faculdade de Direito-RFD-UERJ- Rio de Janeiro, n. 28, dez. 2015

Assim, quando um fato concreto se subsume a um suporte fático abstrato de uma regra, aplica-se essa regra.

Suporte fático abstrato é o formado, em linhas gerais, por aqueles fatos ou atos do mundo que são descritos por determinada norma e para cuja realização ou ocorrência se prevê determinada conseqüência jurídica: preenchido o suporte fático, ativa-se a consequiência jurídica. Suporte fático concreto, intimamente ligado ao abstrato, é a ocorrência concreta, no mundo da vida, dos fatos ou atos que a norma jurídica, em abstrato, jurisdicizou ${ }^{49}$.

No tocante aos direitos fundamentais, leciona Virgilio Afonso da SILVA, que embora o conceito de suporte fático tenha se desenvolvido melhor no âmbito das normas penais, no caso do direito constitucional o conceito de suporte fático dos direitos fundamentais é de suma importância para sua concretização e aplicação.

\footnotetext{
Embora normalmente sem referência à expressão "suporte fático" ou a alguma teoria sobre ele, é comum que se pergunte se esse ou aquele ato, fato ou estado é protegido por essa ou aquela norma que garante um direito fundamental, ou se essa ou aquela ação estatal configura, ou não, uma intervenção nesse âmbito de proteção. (...) Assim, as conseqüências do que se entende por suporte fático e, sobretudo, de sua extensão são enormes e de vital importância na teoria e na prática dos direitos fundamentais ${ }^{50}$.
}

Desta forma, o método de se aplicar um direito fundamental, subsunção, sopesamento, ponderação etc, dependem diretamente da extensão atribuída ao suporte fático dos direitos fundamentais.

Em síntese, um suporte fático restrito restringe a aplicação de um direito fundamental, enquanto um suporte fático amplo otimiza sua aplicação.

Pontifica Virgilio Afonso da SILVA que,

(...) é fácil perceber, que um modelo que se baseia na redução a priori do âmbito de proteção dos direitos fundamentais - um conceito que apresentava exclusivamente teórico-analítico - tende a significar também uma garantia menos eficaz desses direitos nas atividades legislativa e jurisdicional, por excluir da exigência de fundamentação uma série de atos que inegavelmente restringem direitos ${ }^{51}$.

Nessa testilha, as críticas ao modelo puro de regras se fazem mais que necessárias. Apesar de sua vantagem em proporcionar ao jurisdicionado maior

49 SILVA, Virgilio Afonso da. Direitos Fundamentais: conteúdo essencial, restrições e eficácia. São Paulo: Malheiros, 2009, p. 67.

50 Ibidem; p. 68.

51 Ibidem; p. 125. 
Revista da Faculdade de Direito-RFD-UERJ- Rio de Janeiro, n. 28, dez. 2015

segurança jurídica, tendo em vista a previsibilidade que o conteúdo normativo das regras possui quando comparado com o das normas de direitos fundamentais, tal sistema se mostra incapaz de realizar funções imprescindíveis de interpretação e sistematização do ordenamento jurídico desempenhado pelos direitos fundamentais.

Leciona Robert ALEXY que,

Do ponto de vista da vinculação ao texto constitucional, da segurança jurídica e da previsibilidade, um modelo puro de regras é, sem duvidas, a alternativa mais atraente. Os defensores do modelo puro de regras são aqueles que consideram que as normas de direitos fundamentais, por mais que possam ser carentes de complementação, são sempre aplicáveis sem o recurso a ponderações e são, nesse sentido, normas livres de sopesamento ${ }^{52}$.

Mormente a discussão sobre o modelo puro de princípios e o modelo puro de regras, existe ainda um terceiro modelo, chamado misto ou híbrido de princípios e regras que constituem os direitos fundamentais ${ }^{53}$.

Esse modelo compreende que as normas de direitos fundamentais possuem um caráter duplo. Nesse sentido, pontifica ALEXY que o modelo que compreende o ordenamento jurídico como composto por regras e princípios é o que melhor atende a uma Teoria dos Direitos Fundamentais, tendo em vista o reconhecimento de que os direitos fundamentais são normas constitucionais de caráter duplo, ou seja, possuem em suas atribuições tanto regras quanto princípios ${ }^{54}$.

$\mathrm{O}$ fato de que, por meio das disposições de direitos fundamentais, sejam estatuídas duas espécies de normas - as regras e os princípios - é o fundamento do caráter duplo das disposições de direitos fundamentais. Mas isso não significa ainda que também as normas de direitos fundamentais compartilhem desse mesmo caráter duplo. De início elas são ou regras (normalmente incompletas) ou princípios. Mas as normas de direitos fundamentais adquirem um caráter duplo se forem construídas de forma a que ambos os níveis sejam nelas reunidos ${ }^{55}$.

Segundo ALEXY, a vinculação dos níveis da regra e do princípio nas normas de direitos fundamentais surge quando da formulação da norma constitucional é

52 ALEXY, Robert. Teoria dos Direitos Fundamentais. Trad. Virgílio Afonso da Silva. São Paulo: Malheiros, 2008, p. 123.

53 Ibidem; p. 121.

54 Ibidem; p. 144.

55 Ibidem; p. 141. 
Revista da Faculdade de Direito-RFD-UERJ- Rio de Janeiro, n. 28, dez. 2015

incluída "uma cláusula restritiva com a estrutura de princípios, que, por isso, está sujeita a sopesamentos" ${ }^{\circ 6}$.

Em outras palavras as normas de direitos fundamentais de caráter duplo surgem sempre que aquilo que é disposto pela norma fundamental diretamente é restringido por cláusulas que impõem o sopesamento quando colidentes com outras normas de direitos fundamentais de terceiros ou de uma coletividade.

\section{CONCLUSÃO}

Conforme visto a conceituação do que são normas de direitos fundamentais é tarefa das mais difíceis e perpassa pelos mais diferentes aspectos. Abordados aqui pelo prisma de sua evolução histórico-positiva os direitos fundamentais encerram valores universais e atemporais, enfim, valores éticos, humanitários.

Tais valores, na perspectiva de uma nova hermenêutica jurídica, pós-positivista ou neoconstitucionalista, informam e servem de base para interpretar o ordenamento jurídico em face, principalmente, da Constituição.

Para ALEXY existem direitos fundamentais formalmente positivados no texto constitucional e existem direitos fundamentais atribuídos, ou seja, em sentido material implícitos na Constituição.

Dessa forma os direitos fundamentais não encerram um sistema fechado e excludente, mas sim um sistema aberto que possibilita a inclusão de novos direitos fundamentais conforme a evolução histórica humana, sempre lastreado na dignidade da pessoa humana ${ }^{57}$.

\footnotetext{
56 Ibidem; p. 141.

57 Conceitua Ingo Wolfgand SARLET, “(...) temos por dignidade da pessoa humana a qualidade intrínseca e distintiva reconhecida em cada ser humano que o faz merecedor do mesmo respeito e consideração por parte do Estado e da comunidade, implicando nesse sentido, um complexo de direitos e deveres fundamentais que assegurem a pessoa tanto contra todo e qualquer ato de cunho degradante e desumano, como venham a lhe garantir as condições existenciais mínimas para uma vida saudável, além de propiciar e promover sua participação ativa e co-responsável nos destinos da própria existência e da vida em comunhão com os demais seres humanos, mediante o devido respeito aos demais seres que integram a rede da vida". Dignidade da Pessoa Humana e Direitos Fundamentais: na Constituição Federal de 1988. Porto Alegre: Livraria do Advogado, 2009, p. 67.
} 
Revista da Faculdade de Direito-RFD-UERJ- Rio de Janeiro, n. 28, dez. 2015

P á g i n a | 94

Não obstante a imbricada discussão sobre a diferenciação entre regras e princípios, hodiernamente é pacífico que o ordenamento jurídico é formado por ambos, por normas em sentido genérico subdivididas em princípios e regras como espécies normativas.

Sendo as normas de direitos fundamentais, como pontua ALEXY, normas, e encerrarem em si todas as dificuldades que a Ciência do Direito encontra em definir, conceituar normas, também as normas de direitos fundamentais encerram em si um duplo caráter, ou seja, são normas regras e normas princípios.

De forma que, de sua evolução histórico-positiva e da sua conceituação normativa, afere-se que embora exista diferentes teorias explicativas que buscam fundamentar os direitos fundamentais em uma base universal e atemporal, esses direitos em realidade se modificam em cada contexto histórico.

Sendo as necessidades e os interesses da sociedade que definem o conteúdo normativo dos direitos fundamentais, criando-se novos direitos, modificando os já existentes ou extinguindo-os.

Ocorre que, como sublinha BOBBIO, é a luta contínua pelo direito e o aumento da complexidade das relações sócias, principalmente com a intensificação da globalização, que fazem surgir novas demandas, novos direitos, inclusive direitos fundamentais quando a demanda seja a limitação do poder do homem sobre o homem.

De modo que, afere-se que mais importante do que conceituar ou criar novos direitos fundamentais é a efetivação dos já existentes.

\section{REFERÊNCIAS}

ALEXY, Robert. Teoria dos Direitos Fundamentais. Trad. Virgílio Afonso da Silva. São Paulo: Malheiros, 2008.

BARROSO, Luis Roberto. Curso de Direito Constitucional Contemporâneo: os conceitos fundamentais e a construção do novo modelo. São Paulo: Saraiva, 2009. 
Revista da Faculdade de Direito-RFD-UERJ- Rio de Janeiro, n. 28, dez. 2015

P á g i n a | 95

Fundamentos teóricos e filosóficos do novo Direito Constitucional brasileiro. Jus Navigandi, Teresina, ano 6, n. 59, out. 2002. Disponível em: http://jus2.uol.com.br/doutrina/texto.asp?id=3208. Acesso em 22 de jan. 2014.

BOBBIO, Norberto. A Era dos Direitos. Rio de Janeiro: Campos, 1992.

BONAVIDES, Paulo. Curso de Direito Constitucional. São Paulo: Malheiros, 2009.

CARBONELL, Miguel et al. Neoconstitucionalismo (s). Madrid: Trotta, 2003.

DELGADO, Mauricio Godinho. Direitos Fundamentais na Relação de Trabalho. Revista de Direitos e Garantias Fundamentais, n. 2, 2007.

DIDIER JR, Fredie. Curso de Direito Processual Civil: v. 1. Salvador: Juspodivm, 2012.

DIMOULIS, Dimitri; MARTINS, Leonardo. Teoria Geral dos Direitos Fundamentais. São Paulo: RT, 2007.

DWORKIN, Ronald. Levando os direitos a sério. São Paulo: Martins Fontes, 2002.

FACHIN, Zulmar. Curso de Direito Constitucional. Rio de Janeiro: Editora Forense, 2012.

GOMES CANOTILHO, José Joaquim. Direito Constitucional e Teoria da Constituição. Coimbra: Almedina, 1998.

KANT, Immanuel. Resposta a pergunta: que é Ilustração? (1784). Trad. Artur Morão. http://www.lusosofia.net/textos/kant_o_iluminismo_1784.pdf. Acesso em 10/08/13.

LAFER, Celso. Desafios: ética e política. São Paulo: Siciliano, 1995.

MARMELSTEIN, George. Curso de Direitos Fundamentais. São Paulo: Atlas, 2008.

MIRANDA, Jorge. Manual de Direito Constitucional. Coimbra: Coimbra, 1998.

SARLET, Ingo W. A Eficácia dos Direitos Fundamentais. Porto Alegre: Livraria do Advogado, 2009.

Dignidade da Pessoa Humana e Direitos Fundamentais: na Constituição Federal de 1988. Porto Alegre: Livraria do Advogado, 2009.

SILVA, José Afonso. Curso de Direito Constitucional Positivo. São Paulo: Malheiros, 2012. 
SILVA, Virgilio Afonso da. Direitos Fundamentais: conteúdo essencial, restrições e eficácia. São Paulo: Malheiros, 2009.

Interpretação Constitucional e Sincretismo Metodológico. p. 115 - 143. In:

SILVA, Virgílio Afonso da (Org.). Interpretação Constitucional. São Paulo: Malheiros, 2007.

STEINMETZ, Wilson Antonio. Colisão de Direitos Fundamentais e Princípio da Proporcionalidade. Porto Alegre: Livraria do Advogado, 2001.

ZAGREBELSKY, Gustavo. El derecho dúctil. Trotta: Madrid, 2007. 